\title{
Diagnosing schistosomiasis: where are we?
}

\author{
Luciana Inácia Gomes ${ }^{[1]}$, Martin Johannes Enk ${ }^{[2]}$ and Ana Rabello[1]
}

[1]. Laboratório de Pesquisas Clínicas, Centro de Pesquisas René Rachou, Fundação Oswaldo Cruz, Belo Horizonte, MG. [2]. Laboratório de Parasitoses Intestinais e Malacologia, Instituto Evandro Chagas, Secretaria de Vigilância em Saúde, Ministério da Saúde, Ananindeua, PA.

\begin{abstract}
In light of the World Health Organization's initiative to extend schistosomiasis morbidity and mortality control programs by including a disease elimination strategy in low endemic settings, this paper reviews diagnostic tools described during the last decades and provide an overview of ongoing efforts in making an efficient diagnostic tool available worldwide. A literature search on PubMed using the search criteria schistosomiasis and diagnosis within the period from 1978 to 2013 was carried out. Articles with abstract in English and that used laboratory techniques specifically developed for the detection of schistosomiasis in humans were included. Publications were categorized according to the methodology applied (parasitological, immunological, or molecular) and stage of development (in house development, limited field, or large scale field testing). The initial research generated 4,535 publications, of which only 643 met the inclusion criteria. The vast majority (537) of the publications focused on immunological techniques; 81 focused on parasitological diagnosis, and 25 focused on molecular diagnostic methods. Regarding the stage of development, 307 papers referred to in-house development, 202 referred to limited field tests, and 134 referred to large scale field testing. The data obtained show that promising new diagnostic tools, especially for Schistosoma antigen and deoxyribonucleic acid (DNA) detection, which are characterized by high sensitivity and specificity, are being developed. In combination with international funding initiatives these tools may result in a significant step forward in successful disease elimination and surveillance, which is to make efficient tests accessible and its large use self-sustainable for control programs in endemic countries.
\end{abstract}

Keywords: Human schistosomiasis. Diagnosis. Review. Parasitological, immunological and molecular methods.

\section{INTRODUCTION}

During many decades, the schistosomiasis control strategies were based on chemotherapy and aimed to reduce morbidity, mainly in sub-Saharan Africa and other high-burden areas. With the passing time, where significant progress in the control of schistosomiasis and other diseases has been achieved by national control programs (in countries such as Saudi Arabia, the Philippines, Tunisia, Algeria, Japan, Morocco, China, the Caribbean, Venezuela, Egypt, Mauritius, the Islamic Republic of Iran and Brazil) integrated actions in resource capabilities, health educational activities and environmental sanitation were identified as crucial targets for the setting of disease elimination.

In 2008, the World Health Organization (WHO) Department of Control of Neglected Tropical Diseases convened more than 30 international experts and representatives of countries where schistosomiasis has been controlled at varying levels to discuss tools and strategies for monitoring schistosomiasis in low-transmission areas as well as criteria for determining and validating disease elimination ${ }^{1}$. International approval

\footnotetext{
Address to: Ana Rabello. Lab. Pesquisas Clínicas/CPqRR/FIOCRUZ. Av. Augusto de Lima 1715, 30190-002 Belo Horizonte, MG, Brasil. Phone: 5531 3349-7708; Fax: 5531 3295-3115

e-mail: ana@cpqrr.fiocruz.br

Received 31 October 2013

Accepted 2 December 2013
}

of a definition of schistosomiasis elimination, guidelines as to whether or not elimination has been achieved, and a confirmation/verification process to recognize this status has not yet been established and is urgently required ${ }^{2}$.

In this scenario, there is a need for more accurate, standardized and sensitive diagnostic techniques for Schistosoma infection diagnosis. Unfortunately, the technological development of new assays has evolved slowly, partialy because of the current global strategy for schistosomiasis control that is built around preventive chemotherapy, which is the regular administration of drugs to at-risk populations without prior diagnosis ${ }^{3}$, and partially due to the perceived lack of financial return to the diagnostic companies that contributes to making the investments insufficient and discontinuous ${ }^{4}$.

Nonetheless, as result of public, mostly academic investments, a number of diagnostic tests have been developed during the last hundred years. A few of these methods survived the critical non-industrial tactical approach generated by the classic academia-industry disconnect. Consequently, a number of great opportunities may have been buried or left put aside by universities and research institutes. In the same way, hardwon resources may have been spent on attempts to develop less robust assays.

The purpose of this review was to compile information on the laboratorial methods for schistosomiasis diagnosis, considering the steps for test development and focusing on tests that achieved validation steps by large evaluations in field, critically looking at what is available and what has become useful. 


\section{REVIEW METHODOLOGY}

This review was structured around a literature search of the PubMed database using the keywords schistosomiasis and diagnosis. All papers that spanned the period between 1978 and 2013 (October), had an abstract in English and pertained to humans were included. This search generated 4,535 papers, which were screened by title to select only those referring to laboratory diagnosis of Schistosoma mansoni, Schistosoma japonicum and Schistosoma haematobium via parasitological, immunological or molecular methods. In total, 643 papers remained for detailed analysis. Additionally, a standard form to extract data on development step: proof of principle (in house development), specimen banks/limited study groups (limited field study) and population study (large field study) and type of method (parasitological, immunological and molecular tests) was used. The data were entered in a spreadsheet, and Table 1 presents the results. A formal evaluation of test performance and their step of development were considered to identify relevant papers for the review.

\section{FINDINGS}

Egg detection: it is not surprising that the urine filtration and centrifugation methods are effective tools in the diagnosis of $S$. haematobium infections in high prevalence settings. Urine is easily collected but ideally should be collected between 10am and $2 \mathrm{pm}$ due to the circadian pattern of egg excretion. In the case of S. mansoni and S. japonicum detection by stool examination, methods such as the Kato-Katz fecal smear technique ${ }^{5}$ also provide good sensitivity in highly endemic areas. These parasitological methods (urine filtration or Kato-Katz), which cost approximately US\$2, have been widely studied and their usefulness with respect to morbidity control is well established ${ }^{6}$.

The scientific contributions to and progress in schistosomiasis diagnosis in stool samples over the last decades have not resulted in the full availability of new methods; rather, they have resulted mainly in a better understanding of the advantages, limitations and utility of available methods ${ }^{6-13}$. Overall, these studies indicate that an increased sample size or number of examined slides increases a technique's sensitivity, which is of paramount importance in low transmission areas. Unfortunately, this approach limits the operational advantages of these methods, as large-scale fieldwork is required. Nevertheless, the simplicity and the laboratory infrastructure independence of these techniques remain a considerable advantage given that the highest infection and morbidity rates for the disease occur in the poorest and least developed regions.

The development of other coproscopical techniques based on sedimentation ${ }^{14-17}$, centrifugation ${ }^{18,19}$, fluctuation ${ }^{20}$ and miracidium hatching ${ }^{21,22}$, may constitute alternatives to the Kato Katz technique. In general, these methods provide better sensitivity but are more laborious, being more useful for research, schistosomiasis diagnosis in travelers and as additional diagnostic tools for in the depth analysis of infection rates before and after treatment.

Antibody detection: Several immunological methods have been proposed for schistosomiasis diagnosis, but few have reached the large field and validation steps of development. The most commonly and widely used techniques that were validated in large-scale field trials include different formats of enzyme-linked immunosorbent assays (ELISA), the circumoval precipitin test (COPT), the indirect hemagglutination test (IHAT), the indirect immunofluorescence test (IFT) and the skin reaction test.

The immediate response to the Schistosoma adult worm skin test antigen was largely used in China for schistosomiasis investigations in the mid 1950s and for various epidemiological surveys conducted in Puerto Rico in 1963, 1969 and $1976^{23}$. However, the observation that it remains positive for many years after effective chemotherapy, with documented follow-up to ensure cure, limits its usefulness ${ }^{24}$.

Using IFT with adult worm sections, Kanamura et al. ${ }^{25}$ reported that gut-associated fluorescence may occur 44 days after infection and is consistently associated with acute schistosomiasis mansoni infection. A sample is defined as immunoglobulin G-indirect immunofluorescence test (IgG-IFT) positive (frozen sections) when fluorescence is present in the parenchyma and/or gut of the worms and as immunoglobulin $\mathrm{M}$-indirect immunofluorescence test (IgM-IFT) positive (paraffin sections) when fluorescence is only present in the gut of the worms. The IFT has been applied as diagnostic tool in epidemiologic studies of Schistosoma mansoni infection in 1998 in a low endemic area, in Brazil ${ }^{26}$. The prevalence rate was $1.6 \%$ according to the parasitological Kato-Katz method (three slides for one stool sample) and 33.2\% and 33.5\% according to the IgG-IFT and IgM-IFT methods, respectively. This discrepancy was explained by the low diagnostic sensitivity of the parasitological methods for a single stool sample.

TABLE 1 - Classification of the 643 papers that remained in the study for detailed evaluation.

\begin{tabular}{|c|c|c|c|c|}
\hline Phase & \multicolumn{4}{|c|}{ Type of methods } \\
\hline In-house development & 28 & 269 & 10 & 307 \\
\hline Limited field testing & 20 & 169 & 13 & 202 \\
\hline Large scale field testing & 33 & 99 & 2 & 134 \\
\hline
\end{tabular}


The need for an expensive and complex microscope, experienced personnel and delicate reagents limits the use of this technique in endemic areas.

The IHA technique uses lyophilized red blood cells coated with antigen, most commonly crude soluble egg antigen (SEA), for the detection of positive patient sera through agglutination. Due to its simplicity, this technique can be employed in field conditions and requires only basic laboratory equipment. IHA was applied in Chinese population studies as an alternative test to detect human infection with $S$. japonicum. Although this technique shows good levels of sensitivity $(71 \%-97 \%)^{27}$, its specificity is low or varies considerably ${ }^{28}$, making it unsuitable for individual diagnosis and treatment. Its application at the population level is also limited and can only be recommended as an auxiliary method for pre-control use, due to drawbacks, some of them also common in other immunological techniques: a) sensitivity, depending on which standard is applied; b) intrinsic test characteristics, such as antigen and erythrocyte type; c) prevalence of infection in the investigated community; d) possible persistence of positive reactions after treatment; and e) cross-reactions with other helmiths ${ }^{29}$. In the case of infection with $S$. mansoni, a study carried out by Sorgho et al. ${ }^{30}$ obtained similar results, reflecting the limitations listed above.

The circumoval precipitin test (COPT) is based on patient serum precipitation with lyophilized eggs or purified live eggs identified under microscope. This method is useful for the diagnosis of $S$. mansoni and S. japonicum due to its high sensitivity $(92-100 \%)$ and specificity $(96-100 \%)^{31}$. This method was applied in combination with other coproscopic and serologic tests in a modified form as a commercial kit in China ${ }^{24}$ and Venezuela to evaluate low transmission areas ${ }^{31}$. The limitations of this test are that it is time consuming ( $48 \mathrm{hrs)}$ ), is complicated to execute and has a varying period of seroconversion after treatment, according the experiences reported for Venezuela (negative rate of $64 \%$ of patients after 12 months of praziquantel treatment) and China (negative rate of $80-83 \%$ of patients after 4 years of praziquantel treatment).

ELISA is the most commonly used test for the serological detection of schistosomiasis, offering the option of detecting different antibody classes as well as using a wide range of antigens. The detection of Schistosoma antigens was initially based on the use of crude soluble egg antigens (SEA) and soluble adult worms proteins (SWAP). Early studies revealed low specificity, which resulted in the search for purified antigen preparations such as cationic fraction $6(\mathrm{CEF} 6)^{32}$, adult microsomal antigens for $S$. mansoni (MAMA), S. japonicum (JAMA) and S. haematobium (HAMA) ${ }^{33}$, gut associated antigen $31 / 32^{34-36}$ and keyhole limpet hemocyanin (KLH) ${ }^{37}$. The latter has not been evaluated under field conditions and is therefore not included into this review.

CEF6 is a purified antigen from Schistosoma eggs, described by Dunne et al. ${ }^{38}$. In the Mott and Dixon's comparative study ${ }^{39}$, this antigen in an ELISA platform showed $91.7 \%$ of sensitivity and $90 \%$ of specificity and the highest correlation with egg output compared to other antigens. Since that report was published, this antigen was criteriously evaluated in three field studies in S. mansoni endemic areas in Kenya ${ }^{32}$, Saudi Arabia ${ }^{40}$ and Burkina $\mathrm{Faso}^{30}$. The sensitivity in all three assessments was confirmed to be high $(97 \%, 90 \%$ and $97 \%$, respectively); however, the specificity remained low $(59 \%, 55 \%$ and $17.2 \%$, respectively). In all of these studies, the question of the adequacy of the reference tests arose, and the low specificity was attributed to the low sensitivity of the Kato-Katz method, which was used as the gold-standard.

Adult worm microsomal antigens were tested in combination with the Falcon assay screening test-enzymelinked immunosorbent assay (FAST-ELISA) and confirmed by Western Immunoblot. A study in Egypt using HAMA and MAMA in a S. haematobium endemic area as the screening test revealed sensitivity of $83.6 \%$ for MAMA FAST-ELISA and sensitivity of $98.5 \%$ for HAMA FAST-ELISA. By adding the Western blot technique to HAMA FAST-ELISA for additional analysis, all egg-passing individuals were identified, revealing $100 \%$ of sensitivity and $59.4 \%$ of specificity, compared to egg detection in urine ${ }^{41}$. A systematic serosurvey conducted in 1995 in almost all municipalities in Puerto Rico evaluated 2,955 healthy donor plasma samples using MAMA FASTELISA, followed by enzyme-linked immunoelectrotransfer blot (EITB) confirmation. The data showed that $15.4 \%$ of samples were FAST-ELISA positive, and $10.6 \%$ were confirmed by EITB. The highest seroprevalence rates (21.1-38.5\%) were concentrated in 17 municipalities, which accounted for $48 \%$ of all seropositive samples and $18 \%$ of the total population of Puerto Rico ${ }^{42}$. Variations in the results obtained from these purified preparations were observed in different settings and thus limit conclusions about test accuracy and performance at this stage. A recent study by Abdel-Fattah et al. ${ }^{43}$ using a purified a HAMA antigen that is highly specific for $S$. haematobium and a new standard curve suggests that FAST-HAMA can be used as a diagnostic assay for $S$. haematobium infection, as it showed a positivity rate of $95 \%$. Nevertheless, additional studies are necessary to establish its specificity and its performance in field conditions.

In the case of 31/32 kilodalton adult Schistosoma proteins, population studies on $S$. mansoni in Sudan and $S$. japonicum in China revealed high sensitivity but low specificity ${ }^{36}$. This low specificity was justified by various factors, such as crossreaction, infection with non-human Schistosoma species, and lack of sensitivity of the parasitological reference test. Unfortunately, further evaluations of this methodology's accuracy are not available, and this issue remains unresolved.

Rapid tests for antibody detection in new assay formats have been reported for $S$. japonicum, including the dot immunogold filtration assay ${ }^{44}$, the silver-enhanced colloidal gold metalloimmunoassay ${ }^{45}$ and the colloidal dye immunofiltration assay $^{46}$. A western blot assay has also been evaluated for anti-S. mansoni antibody detection ${ }^{47}$ and an immunoblot assay of $S$. mansoni, S. intercalatum and $S$ haematobium membrane antigens against Schistosoma infected patient sera has been tested ${ }^{48}$. These new formats use crude antigens and still need to be validated in large-scale field trials. 
Recently, a novel rapid dipstick with latex immunochromatographic assay (DLIA) using $S$. japonicum SEA as antigen was developed to detect anti-S. japonicum antibodies in human serum. In a Schistosoma-endemic area in China ${ }^{49}$ the test was evaluated on 102 serum samples that had tested positive for schistosomiasis by the Kato-Katz method (epg: $8 \sim 1352$ ) and 275 serum samples from healthy individuals (negative for schistosomiasis on the Kato-Katz method), showing $95.1 \%$ (97/102) of sensitivity and 94.9\% (261/275) of specificity. Fifteen clonorchiosis, 11 intestinal nematode and 8 Angiostrongylus cantonensis samples were tested with DLIA and showed no signs of cross-reactivity. When 19 paragonimiasis samples were tested by DLIA, the cross-reaction rate was $42.1 \%(8 / 19)$. Additionally, serum samples (333 in total) from a schistosomiasis endemic area in China were tested by the DLIA and Kato-Katz methods. The positive rate was $21.2 \%(72 / 333)$ by DLIA and $3.9 \%(13 / 333)$ by Kato-Katz. DLIA showed $92.3 \%$ of sensitivity and $81.3 \%$ of specificity. In the same study, an ELISA-SEA test was performed, and there were no significant differences in positive and negative detection rates between the two serological methods. ELISA reagents require cold-chain logistics, and the test takes several hours to complete. One important advantage of DLIA is cost, as the latex microspheres produced in China are considerably less expensive than enzyme conjugates or colloidal gold. In addition, the control band on each dipstick contributes to the quality control of the assay. A dipstick dye immunoassay (DDIA) that has recently become commercially available in China, was evaluated in a cross-sectional survey that included 6,285 individuals aged 6-65 years from seven villages with low schistosomiasis endemicity. Stool samples were collected and examined by the Kato-Katz method and the miracidium hatching technique. Using the stool examination as the gold reference, DDIA exhibited a high overall sensitivity of $91.3 \%$ and a high negative predictive value (mean, $99.3 \%$ ), but $53.1 \%$ of specificity. The authors conclude that the moderate DDIA specificity was mainly caused by the stool examination low sensitivity and by the high frequency of previous exposure to schistosomes. As a rapid, simple, apparatus-free and sensitive assay, DDIA is feasible and of practical use as a screening tool in areas of low S. japonicum ${ }^{50}$ endemicity. As for other antibodybased tests, specificity remains to be clarified.

Recombinant antigens and those derived from proteomic studies constitute a new promising line of research in the diagnosis of schistosomiasis, but they are still in the experimental phase, awaiting further improvement and validation. One example is the rSi26-Si32 fusion protein, which is used mainly with a magnetic bead-based immunoassay ${ }^{51}$ that was developed for chronic schistosomiasis japonica immunodiagnosis in China.

Antigen detection: Similarly, a number of assays to detect circulating antigen have been described. The detection of circulating anodic antigen (CAA) and circulating cathodic antigen (CCA) in serum and urine, using the ELISA ${ }^{52,53}$ or dipstick platforms ${ }^{54}$, and antigen capture with monoclonal antibodies ${ }^{55}$ have been the most widely studied methods. Their main advantages are high specificity, positive correlation with worm burden, and the possibility for estimation of infection intensity $^{56-58}$. Moreover, circulating Schistosoma antigens disappear rapidly after treatment and can therefore be used for assessment of cure ${ }^{59}$.

Overall, the sensitivity of antigen detection is low in low endemic areas, similar to the sensitivity obtained with stool examination and urine filtration. Therefore, this technique can be used as a substitute for parasitological examinations in settings with high infection rates or as a complementary method in settings with low infection rates ${ }^{60}$.

To date, currently available CCA tests have been shown to have moderate to good reliability in detecting $S$. mansoni $i^{5,61-65}$ but poor performance in detecting S. haematobium ${ }^{61,66-69}$. Recently, the Bill \& Melinda Gates Foundation sponsored evaluation studies on the accuracy of the urine CCA tests for determining schistosomiasis prevalence in young children in African countries. The main results were obtained by evaluating the CCA urine cassette assay, a commercial kit produced in South Africa, performed at ambient temperature according to the manufacturer's instructions. In Côte d'Ivoire, the sensitivity of triplicate Kato-Katz was $47.9 \%, 73.9 \%$ and $94.2 \%$ for the settings A, B (both endemic for S. mansoni) and $\mathrm{C}$ (where $S$. haematobium co-exists) in comparison with one CCA test, that performed at sensitivity levels of 56.3, 69.6 and $89.6 \%$, respectively. The specificity of CCA test was moderate $(76.9-84.2 \%)^{70}$. In the Lake Victoria region of western Kenya, where $S$. mansoni infection is prevalent and S. haematobium is not, CCA test was compared to Kato-Katz in 484 children, with sensitivity of $94.2 \%$ and specificity of $59.4 \%$. The authors also utilized latent class analysis (LCA) incorporating the CCA, Kato-Katz and schistosomespecific antibody results to determine their sensitivities and specificities. By LCA, CCA test had $96.3 \%$ of sensitivity and $74.7 \%{ }^{71}$ of specificity. In the same line of research, an independent study conducted in southern Sudan showed a moderate performance (sensitivity of $89.1 \%$ and specificity of $74.2 \%$ ) for the CCA test in an evaluation of 373 children. For the authors, this may be a slight underestimation of the true CCA accuracy, as only one single stool and urine samples were examined by microscope ${ }^{72}$.

DNA detection: During the last decade, polymerase chain reaction (PCR)-based assays have become more accessible and have been applied in the diagnosis of infectious and parasitic diseases. According to Reithinger \& Dujardin ${ }^{73}$ PCR assays can be divided in three distinct formats, namely the mid tech approach, represented by PCR, the high tech, represented by real-time PCR and the low tech, represented by the loop mediated isothermal amplification (LAMP).

In the specific case of human schistosomiasis, the first application of PCR as a diagnostic tool in an endemic area was a PCR assay for S. mansoni DNA detection in stool samples ${ }^{74,75}$. The target DNA is a tandem repeat 121 base pair (bp) sequence ${ }^{76}$. Comparing the PCR assay to stool examinations by the KatoKatz technique, the PCR assay showed sensitivity of $96.7 \%$ and specificity of $88 \%$ when applied among 194 inhabitants from a Brazilian endemic area. The assay showed the detection limit (analytical sensitivity) of $1 \mathrm{fg}$ of S. mansoni genomic DNA and no 
cross-reaction (analytical specificity) with DNA from four other helminthes: Ascaris lumbricoides, Ancylostoma duodenales, Taenia solium and Trichiuris trichiuria. The authors emphasize that this technique might prove to be useful in low transmission settings due to its high sensitivity (96,7\%) compared to the $79 \%$ of sensitivity obtained by stool examination, when the criteria for positivity was determined as positivity by any of the direct methods. The sensitivity of this technique was reevaluated in other studies in which it was applied to preselected individuals with low worm burden ${ }^{77,78}$ and schistosomiasis positive patients after treatment ${ }^{79}$. Under these specific conditions, both studies confirmed the high sensitivity of the PCR assay.

Furthermore, this assay using a tandem repeat 121 base pair (bp) sequence was improved by the simplification of PCR product visualization with the polymerase chain reactionenzyme-linked immunosorbent assay (PCR-ELISA) ${ }^{80}$, and with oligochromatography-polymerase chain reaction $(\mathrm{OC}-\mathrm{PCR})^{81}$ and a modified DNA extraction procedure ${ }^{82}$ without losing its high sensitivity. Recently, the same DNA sequence was used successfully in the detection of Schistosoma DNA in plasma by Wichmann et al. ${ }^{83}$ and in urine samples by Enk et al. ${ }^{84,85}$ and Ibironke et al. ${ }^{86}$.

PCR was also applied for species-specific DNA amplification. In a study reported by Sandoval et al ${ }^{87}$ this technique was used for genus- and species-specific amplification of the main four Schistosoma species that cause disease in humans and S. bovis. Using easy-to-handle urine samples from 50 healthy donors, 18 patients with schistosomiasis (6 with $S$. mansoni infection, 10 with $S$. haematobium infection and 2 with mixed infection) and 29 with other parasite infections, $94.4 \%$ of sensitivity and $99.9 \%$ of specificity were found for a genus specific primer and a S. mansoni species-specific PCR revealed sensitivity of $100 \%$ and specificity of $98.9 \%$. Recently, a PCR assay to detect $S$. mansoni infection (species-specific DNA) from filtered urine samples in Zambia proved to be an effective means to detect low intensity infection and would enhance the effectiveness of surveillance and control programs of schistosomiasis ${ }^{88}$.

The high tech approach of real-time PCR systems has recently been applied to parasitology, as they are powerful alternative tools for quantifying parasitic load. These assays are performed with a single setup and dye detection within a closed tube, which decreases the risk of DNA contamination. The first method described for schistosomiasis diagnosis used SYBER Green dye for the detection of $S$. mansoni, targeting a small 96bp fragment on the small subunit-ribosomal ribonucleic acid (SSU rRNA) gene ${ }^{89}$. DNA extracts from adult S. mansoni worms were used in the system evaluation, showing a parasite DNA detection limit of $10 \mathrm{fg}$. The authors emphasize the potential of this method to detect $S$. mansoni DNA in different biological samples, such as human feces, snails and water. In addition, it can be useful to quantify parasite burden in human and snail infection.

Another real-time PCR approach was described for $S$. japonicum diagnosis in stool samples. Similar to the previous method, SYBER Green dye was used as an intercalating dye into double-strand DNA to measure the change in fluorescence after each PCR cycle. In artificially spiked stool samples, this method demonstrated high sensitivity, even in samples containing a single egg $^{90}$. The same research group used this test in a comparative study in China among 1,727 participants from an endemic area. In China, results obtained with the commonly used algorithm for schistosomiasis control, consisting of an initial antibody screening and subsequent confirmation with Kato-Katz stool examination, were compared to results obtained by substituting the confirming coproscopical test by PCR. The results revealed an increase from 22 to 50 positives when PCR replaced the Kato Katz technique. In conclusion, considering the decrease in prevalence and infection intensity, the authors emphasize that the gains in sensitivity must be weighed against additional costs and operational implications of both choices ${ }^{91}$.

In Ghana, a real time PCR system using TaqMan chemistry and primers, as well as a probe based on the internaltranscribed-spacer-2 (ITS-2) for S. haematobium detection in urine samples of 153 children, was studied by Obeng et al. ${ }^{68}$. A total of 66 positive participants were detected by PCR, and 74 were detected by urine microscopy, indicating sensitivity of $89.2 \%$ and specificity of $100 \%$. It is worth noting that all 8 cases that were missed by PCR had less than 50 eggs $/ 10 \mathrm{ml}$ urine in the microscopic examination, a finding that can be explained by the very small amount $(200 \mu \mathrm{l})$ of urine used for PCR. This same real time PCR system was recently applied in epidemiological survey of schistosomiasis in Ghana and proved to be a powerful tool, providing more precise and sensitive results than microscopy ${ }^{92}$.

Recently, Cnops et al..$^{93}$ developed a similar assay using TaqMan chemistry and the 28S ribosomal RNA gene as target to detect different Schistosoma species for diagnosis in international travelers and migrants. After showing an analytical sensitivity of 0.2 eggs per gram of feces, the assay's performance was evaluated in feces, urine, and serum samples from patients presenting at the outpatient clinic of the Institute of Tropical Medicine in Antwerp (Belgium). Schistosoma DNA was detected in 76 fecal $(50 \%)$ and five urine (15.6\%) samples, of which nine and one, respectively, were not detected by standard microscopy. Only two of the 38 serum samples from patients with confirmed schistosomiasis were PCR positive. The same group ${ }^{94}$ developed a real-time PCR targeting the Dra1 sequence for S. haematobium-specific detection in urine, feces, and particularly serum of international travelers and migrants. The assay revealed a positive result in 7/7 urine samples, 11/11 stool samples and 1/1 biopsy containing $S$. haematobium eggs as demonstrated by microscopy and in 22/23 serum samples from patients with parasitological confirmed S. haematobium infection. Schistosoma haematobium DNA was additionally detected by PCR in 7 urine, 3 stool and 5 serum samples of patients suspected of having schistosomiasis without egg excretion in urine and feces.

The multiplex format of real time PCR was tested in fecal samples by Ten Hove et al. ${ }^{95}$ in 88 participants from a northern Senegalese village that is endemic for both $S$. mansoni and $S$. haematobium. The system uses TaqMan probes as the detection 
chemistry and primers, and probes were designed to target the cytochrome c oxidase subunit 1 ( $\operatorname{cox} 1)$ gene in the mitochondrial genome because this DNA sequence shows sufficient divergence between separate Schistosoma species. The analytical specificity was evaluated using 150 DNA controls derived from a wide range of intestinal microorganisms, and amplification was not detected in any of these samples. Although an in-depth analysis of this multiplex real time PCR system regarding its sensitivity of and specificity in comparison to microscopic stool and urine analysis was not provided by the authors, the overall test performance revealed that $70 \%(79.5 \%)$ of the 88 subjects were positive by microscopy, whereas $74(84.1 \%)$ were found to be PCR positive.

The low tech PCR approach, loop mediated isothermal amplification (LAMP) developed by Notomi et al. ${ }^{96}$ was recently used for the detection of $S$. japonicum DNA in rabbit fecal and serum samples, as well as in 50 human serum samples ${ }^{97}$. The analytical test evaluation revealed high analytical sensitivity, detecting $0.08 \mathrm{fg}$ of DNA, and no cross-reaction was found with S. mansoni and Clonorchis sinensis. The evaluation of the 50 human samples showed sensitivity of $96.7 \%$ and specificity of $100 \%$. This initial result indicates that LAMP might become a useful tool for routine diagnosis and therapeutic evaluation due to the practicality of using a simple water bath for amplification and a dye for visualization.

The role of PCR-based assays in schistosomiasis diagnosis outside of research settings remains to be fully defined, despite their significant potential in low transmission settings and in situations where high sensitivity and specificity are required. Additionally, as cost efficiency improves through increased demand for molecular diagnosis of other infectious diseases such as human immunodeficiency virus (HIV) and tuberculosis, PCR assays are expected to become more affordable and may constitute a new available tool for schistosomiasis diagnosis.

Futures perspectives of novel funding schemes and product development partnerships: there are now more funding agencies in the diagnostic research and development fields for neglected tropical diseases, notably the Bill \& Melinda Gates Foundation (BMGF). The initiatives are mainly concentrated on the development of point-of-care (POC) diagnostics that can rapidly and accurately identify infections in patients, promoting the use of standardized and validated commercial kits and applying molecular high-throughput multiplexing assays for simultaneous diagnosis of helminths and intestinal protozoan infections, at least in return travelers at specialized laboratories in the industrialized world ${ }^{4,98-103}$, but hopefully not limited to these scenarios.

Importantly, the BMGF, through a five-year grant to the University of Georgia Research Foundation, sponsored the Schistosomiasis Consortium for Operational Research and Evaluation (SCORE) (http://score.uga.edu/). The Consortium was established in December 2008 to answer strategic questions about schistosomiasis control and elimination. In 2010, SCORE funded a 5-country (Cameroon, Ethiopia, Cote d'Ivoire, Kenya, and Uganda) evaluation of the CCA urine strip test for the diagnosis of S. manoni in low and moderate endemic areas, as well as in mixed S. manosni-S. haematobium foci. Based on the preliminary study results (see the Antigen Detection section), SCORE suggested that a single urine examination using a commercially available POC/CCA cassette-based test instead of a single stool examination by the Kato-Katz method could be used to assess $S$. mansoni prevalence in school age children. Should these validations prove successful, efforts should be made to further reduce the cost per test strip (ideally below US\$2.00) to make this technique useful as a POC diagnostic approach in resource-constrained settings.

Also in 2003, the BMGF offered a 5-year start-up grant, which helped to set up the Foundation for Innovative New Diagnostics (FIND; http://www.finddiagnostics.org/), which has gradually expanded its portfolio of activities with a growing emphasis on developing and validating novel diagnostics for neglected tropical diseases ${ }^{98}$.

Most importantly, technological advancement is only one aspect of this issue. A solid governmental strategy must integrate diagnosis and treatment into the primary healthcare system. In China, the benefit of this integration was clearly demonstrated by Guo et al. ${ }^{104}$, who reported that the cost of a strategy based on passive chemotherapy and health education was approximately half the cost of mass drug distribution in two villages with $11 \%$ and $12.3 \%$ prevalence of $S$. mansoni infection, with similar treatment coverage.

Even when a test with acceptable performance is available, laboratory capacity and local autonomy are essential to carrying out and maintaining realistic, collaborative and self-sustained control programs.

\section{CONFLICT OF INTEREST}

The authors declare that there is no conflict of interest.

\section{REFERENCES}

1. World Health Organization (WHO). Elimination of schistosomiasis from low transmission areas. Report of a WHO Informal Consultation, Salvador, Bahia, Brazil, 18-19 August 2008.

2. Rollinson D, Knopp S, Levitz S, Stothard JR, Tchuenté LA, Garba A, et al. Time to set the agenda for schistosomiasis elimination. Acta Trop 2013; 128:423-440.

3. Utzinger J, N'goran EK, Caffrey CR, Keiser J. From innovation to application: social-ecological context, diagnostics, drugs and integrated control of schistosomiasis. Acta Trop 2011; 120 (suppl I): 121-137.

4. Peeling RW, Nwaka S. Drugs and diagnostic innovations to improve global health. Infect Dis Clin North Am 2011; 25:693-705.

5. Katz N, Chaves A, Pellegrino J. A simple device for quantitative stool thick-smear technique in Schistosomiasis mansoni. Rev Inst Med Trop Sao Paulo 1972; 14:397-400.

6. Enk MJ, Lima AC, Drummond SC, Schall VT, Coelho PM. The effect of the number of stool samples on the observed prevalence and the infection intensity with Schistosoma mansoni among a population in an area of low transmission. Acta Trop 2008; 108:222-228.

7. Engels D, Sinzinkayo E, Gryseels B. Day-to-day egg count fluctuation in Schistosoma mansoni infection and its operational implications. Am J Trop Med Hyg 1996; 54:319-24. 
8. Engels D, Sinzinkayo E, De Vlas SJ, Gryseels B. Intraspecimen fecal egg count variation in Schistosoma mansoni infection. Am J Trop Med Hyg 1997; 57:571-577.

9. Ross AG, Li Y, Sleigh AC, Williams GM, McManus DP. Faecal egg aggregation in humans infected with Schistosoma japonicum in China. Acta Trop 1998; 70:205-210.

10. Kongs A, Marks G, Verlé P, Van der Stuyft P. The unreliability of the Kato-Katz technique limits its usefulness for evaluating $S$. mansoni infections. Trop Med Int Health 2001; 6:163-169.

11. Utzinger J, Booth M, N'Goran EK, Müller I, Tanner M, Lengeler C. Relative contribution of day-to-day and intra-specimen variation in faecal egg counts of Schistosoma mansoni before and after treatment with praziquantel. Parasitology 2001; 122:537-544.

12. Berhe N, Medhin G, Erko B, Smith T, Gedamu S, Bereded D, et al. Variations in helminth faecal egg counts in Kato-Katz thick smears and their implications in assessing infection status with Schistosoma mansoni. Acta Trop 2004; 92:205-212.

13. Lin DD, Liu JX, Liu YM, Hu F, Zhang YY, Xu JM, et al. Routine KatoKatz technique underestimates the prevalence of Schistosoma japonicum: a case study in an endemic area of the People's Republic of China. Parasitol Int 2008; 57:281-286.

14. Polderman AM, Panday UG, Ramkisoen S, van Lieshout L, Oostburg BF. A sedimentation-selective filtration method for the diagnosis of light infections with Schistosoma mansoni. Acta Trop 1994; 58:221-227.

15. Ebrahim A, El-Morshedy H, Omer E, El-Daly S, Barakat R. Evaluation of the Kato-Katz thick smear and formol ether sedimentation techniques for quantitative diagnosis of Schistosoma mansoni infection. Am J Trop Med Hyg 1997; 57:706-708.

16. Borel E, Etard JF, Addo A, Diakite M. Comparison of a digestionsedimentation technique with the Kato-Katz technique in the detection and quantification of $S$. mansoni eggs in light to moderate infections. Parasite 1999; 6:175-178

17. Coelho PM, Jurberg AD, Oliveira AA, Katz N. Use of a saline gradient for the diagnosis of schistosomiasis. Mem Inst Oswaldo Cruz 2009; 104:720-723.

18. Eberl M, al-Sherbiny M, Hagan P, Ljubojevic S, Thomas AW, Wilson RA. A novel and sensitive method to monitor helminth infections by faecal sampling. Acta Trop 2002; 83:183-187.

19. Gomes JF, Hoshino-Shimizu S, Dias LC, Araujo AJ, Castilho VL, Neves FA. Evaluation of a novel kit (TF-Test) for the diagnosis of intestinal parasitic infections. J Clin Lab Anal 2004; 18:132-138.

20. Glinz D, Silué KD, Knopp S, Lohourignon LK, Yao KP, Steinmann P, et al. Comparing diagnostic accuracy of Kato-Katz, Koga agar plate, ether-concentration, and FLOTAC for Schistosoma mansoni and soiltransmitted helminths. PLoS Negl Trop Dis 2010; 4(7):e754.

21. Hubbard A, Liang S, Maszle D, Qiu D, Gu X, Spear RC. Estimating the distribution of worm burden and egg excretion of Schistosoma japonicum by risk group in Sichuan Province, China. Parasitology 2002;125:221-231.

22. Jurberg AD, Oliveira AA, Lenzi HL, Coelho PM. A new miracidia hatching device for diagnosing schistosomiasis. Mem Inst Oswaldo Cruz 2008; 103:112-114.

23. Negrón-Aponte H, María Nazario C. The 1976 skin test survey for schistosomiasis in Puerto Rico. Bol Asoc Med P R 1979; 71:17-25.

24. Zhu YC. Immunodiagnosis and its role in schistosomiasis control in China: a review. Acta Trop 2005; 96:130-136.

25. Kanamura HY, Hoshino-Shimizu S, Camargo ME, Silva LC. Class specific antibodies and fluorescent staining patterns in acute and chronic forms of schistosomiasis mansoni. Am J Trop Med Hyg 1979; 28: 242-248.

26. Burlandy-Soares LC, Souza Dias LC, Kanamura HY, Oliveira EJ, Ciaravolo RM. Schistosomiasis mansoni: follow-up of control program based on parasitologic and serologic methods in a Brazilian community of low endemicity. Mem Inst Oswaldo Cruz 2003; 98:853-859.

27. Yu JM, de Vlas SJ, Jiang QW, Gryseels B. Comparison of the Kato-Katz technique, hatching test and indirect hemagglutination assay (IHA) for the diagnosis of Schistosoma japonicum infection in China. Parasitol Int 2007; 56:45-49.

28. Zhou YB, Yang MX, Wang QZ, Zhao GM, Wei JG, Peng WX, et al. Field comparison of immunodiagnostic and parasitological techniques for the detection of Schistosomiasis japonica in the People's Republic of China. Am J Trop Med Hyg 2007; 76:1138-1143.

29. Zhou YB, Yang MX, Tao P, Jiang QL, Zhao GM, Wei JG, et al. A longitudinal study of comparison of the Kato-Katz technique and indirect hemagglutination assay (IHA) for the detection of schistosomiasis japonica in China, 2001-2006. Acta Trop 2008; 107:251-254.

30. Sorgho H, Bahgat M, Poda JN, Song W, Kirsten C, Doenhoff MJ, et al. Serodiagnosis of Schistosoma mansoni infections in an endemic area of Burkina Faso: performance of several immunological tests with different parasite antigens. Acta Trop 2005; 93:169-180.

31. Alarcón de Noya B, Ruiz R, Losada S, Colmenares C, Contreras R, Cesari IM, et al. Detection of schistosomiasis cases in low-transmission areas based on coprologic and serologic criteria The Venezuelan experience. Acta Trop 2007; 103:41-49.

32. Doenhoff MJ, Butterworth AE, Hayes RJ, Sturrock RF, Ouma JH, Koech D, et al. Seroepidemiology and serodiagnosis of schistosomiasis in Kenya using crude and purified egg antigens of Schistosoma mansoni in ELISA. Transactions of the Royal Society of Tropical Medicine and Hygiene, $1993 ; 87: 42-48$.

33. Tsang VC, Hancock K, Kelly MA, Wilson BC, Maddison SE. Schistosoma mansoni adult microsomal antigens, a serologic reagent. II. Specificity of antibody responses to the $S$. mansoni microsomal antigen (MAMA). Journal of Immunology, 1983; 130:1366-1370.

34. Ruppel A, Diesfeld HJ, Rother U. Immunoblot analysis of Schistosoma mansoni antigens with sera of schistosomiasis patients: diagnostic potential of an adult schistosome polypeptide. Clin Exp Immunol 1985; 62:499-506.

35. Ruppel A, Shi YE, Wei DX, Diesfeld HJ. Sera of Schistosoma japonicuminfected patients cross-react with diagnostic $31 / 32 \mathrm{kD}$ proteins of S. mansoni. lin Exp Immunol 1987; 69:291-298.

36. Ruppel A, Idris MA, Sulaiman SM, Hilali AM. Schistosoma mansoni diagnostic antigens ( $\mathrm{Sm} \mathrm{31/12):} \mathrm{a} \mathrm{sero-epidemiological} \mathrm{study} \mathrm{in} \mathrm{the}$ Sudan. Trop Med Parasitol 1990; 41:127-130.

37. Mansour MM, Ali PO, Farid Z, Simpson AJ, Woody JW. Serological differentiation of acute and chronic schistosomiasis mansoni by antibody responses to keyhole limpet hemocyanin. Am J Trop Med Hyg 1989; 41:338-344.

38. Dunne DW, Bain J, Lillywhite J, Doenhoff MJ. The stage-, strain- and species-specificity of a Schistosoma mansoni egg antigen fraction (CEF6) with serodiagnostic potential. Trans R Soc Trop Med Hyg 1984; 78:460470.

39. Mott KE, Dixon H. Collaborative study on antigens for immunodiagnosis of schistosomiasis. Bull World Health Organ 1982; 60:729-753.

40. Ghandour AM, Tricker K, Doenhoff MJ, al-Robai AA, Banaja AA. An enzyme-linked immunosorbent assay using Schistosoma mansoni purified egg antigen for the diagnosis of schistosomiasis in Saudi Arabia. Trans R Soc Trop Med Hyg 1997; 91:287-289.

41. Al-Sherbiny MM, Osman AM, Hancock K, Deelder AM, Tsang VC. Application of immunodiagnostic assays: detection of antibodies and circulating antigens in human schistosomiasis and correlation with clinical findings. Am J Trop Med Hyg 1999; 60:960-966.

42. Tsang VC, Hillyer GV, Noh J, Vivas-Gonzalez BE, Ahn LH, Pilcher JB, et al. Geographic clustering and seroprevalence of schistosomiasis in Puerto Rico (1995). Am J Trop Med Hyg 1997; 56:107-112.

43. Abdel-Fattah M, Al-Sherbiny M, Osman A, Charmy R, Tsang V. Improving the detection limit of quantitative diagnosis of anti-S. haematobium antibodies using Falcon Assay Screening Test (FAST) ELISA by developing a new standard curve. Parasitol Res 2011; 108:1457-1463.

44. Wen LY, Chen JH, Ding JZ, Zhang JF, Lu SH, Yu LL, et al. Evaluation on the applied value of the dot immunogold filtration assay (DIGFA) for rapid detection of anti-Schistosoma japonicum antibody. Acta Tropica 2005; 96:142-147. 
45. Chu X, Xiang ZF, Fu X, Wang SP, Shen GL, Yu RQ. Silver-enhanced colloidal gold metalloimmunoassay for Schistosoma japonicum antibody detection. J Immunol Methods 2005; 301:77-88.

46. Xiao X, Wang T, Ye H, Qiang G, Wei H, Tian Z. Field evaluation of a rapid, visually-read colloidal dye immunofiltration assay for Schistosoma japonicum for screening in areas of low transmission. Bull World Health Organ 2005; 83:526-533.

47. Sulahian A, Garin YJ, Izri A, Verret C, Delaunay P, van Gool T, et al. Development and evaluation of a Western blot kit for diagnosis of schistosomiasis. Clinical and Diagnostic Laboratory Immunology 2005; 12:548-551

48. Cesari IM, Ballen DE, Mendoza L, Ferrer A, Pointier JP, Kombila M, et al. Immunoblot analysis of membrane antigens of Schistosoma mansoni, Schistosoma intercalatum, and Schistosoma haematobium against Schistosoma-infected patient sera. Parasitol Res 2010; 106:12251231.

49. Yu LL, Ding JZ, Wen LY, Lou D, Yan XL, Lin LJ, et al. Development of a rapid dipstick with latex immunochromatographic assay (DLIA) for diagnosis of schistosomiasis japonica. Parasit Vectors 2011; 4:157.

50. Xu J, Feng T, Lin DD, Wang QZ, Tang L, Wu XH, et al. Performance of a dipstick dye immunoassay for rapid screening of Schistosoma japonicum infection in areas of low endemicity. Parasit Vectors 2011; 4:87.

51. Yu Q, Yang H, Feng Y, Yang X, Zhu Y. Magnetic affinity enzyme-linked immunoassay based on recombinant $26 \mathrm{kDa}$ glutathione-S-transferase for serological diagnosis of schistosomiasis japonica. Acta Trop 2012; 124:199-202.

52. Deelder AM, De Jonge N, Fillié YE, Kornelis D, Helaha D, Qian ZL, et al. Quantitative determination of circulating antigens in human schistosomiasis mansoni using an indirect hemagglutination assay. Am J Trop Med Hyg 1989; 40:50-54.

53. Deelder AM, De Jonge N, Boerman OC, Fillié YE, Hilberath GW, Rotmans JP, et al. Sensitive determination of circulating anodic antigen in Schistosoma mansoni infected individuals by an enzyme-linked immunosorbent assay using monoclonal antibodies. Am J Trop Med Hyg $1989 ; 40: 268-272$.

54. Van Dam GJ, Wichers JH, Ferreira TM, Ghati D, van Amerongen A, Deelder AM. Diagnosis of schistosomiasis by reagent strip test for detection of circulating cathodic antigen. J Clin Microbiol 2004; 42:54585461.

55. De Jonge N, Kremsner PG, Krijger FW, Schommer G, Fillié YE, Kornelis $\mathrm{D}$, et al. Detection of the schistosome circulating cathodic antigen by enzyme immunoassay using biotinylated monoclonal antibodies. Trans R Soc Trop Med Hyg 1990; 84:815-818.

56. Van Lieshout L, Panday UG, De Jonge N, Krijger FW, Oostburg BF, Polderman AM, et al. Immunodiagnosis of schistosomiasis mansoni in a low endemic area in Surinam by determination of the circulating antigens CAA and CCA. Acta Trop 1995; 59:19-29.

57. Van Lieshout L, Polderman AM, De Vlas SJ, De Caluwé P, Krijger FW, Gryseels B, et al. Analysis of worm burden variation in human Schistosoma mansoni infections by determination of serum levels of circulating anodic antigen and circulating cathodic antigen. J Infect Dis $1995 ; 172: 1336-1342$.

58. Polman K, Stelma FF, Gryseels B, Van Dam GJ, Talla I, Niang M, et al. Epidemiologic application of circulating antigen detection in a recent Schistosoma mansoni focus in northern Senegal. Am J Trop Med Hyg 1995; 53:152-157.

59. El-Morshedy H, Kinosien B, Barakat R, Omer E, Khamis N, Deelder AM, et al. Circulating anodic antigen for detection of Schistosoma mansoni infection in Egyptian patients. Am J Trop Med Hyg 1996; 54:149-153.

60. van Lieshout L, Polderman AM, Deelder AM. Immunodiagnosis of schistosomiasis by determination of the circulating antigens CAA and CCA, in particular in individuals with recent or light infections. Acta Trop 2000; 77:69-80

61. Stothard JR, Kabatereine NB, Tukahebwa EM, Kazibwe F, Rollinson D, Mathieson W, et al. Use of circulating cathodic antigen (CCA) dipsticks for detection of intestinal and urinary schistosomiasis. Acta Trop 2006; 97:219-228.
62. Legesse M, Erko B. Field-based evaluation of a reagent strip test for diagnosis of Schistosoma mansoni by detecting circulating cathodic antigen in urine before and after chemotherapy. Trans R Soc Trop Med Hyg 2007; 101:668-673.

63. Legesse M, Erko B. Field-based evaluation of a reagent strip test for diagnosis of schistosomiasis mansoni by detecting circulating cathodic antigen (CCA) in urine in low endemic area in Ethiopia. Parasite 2008; 15:151-155.

64. Standley C, Lwambo N, Lange C, Kariuki H, Adriko M, Stothard J. Performance of circulating cathodic antigen (CCA) urine-dipsticks for rapid detection of intestinal schistosomiasis in schoolchildren from shoreline communities of Lake Victoria. Parasit Vectors 2010; 3:7.

65. Standley CJ, Adriko M, Arinaitwe M, Atuhaire A, Kazibwe F, Fenwick A, et al. Epidemiology and control of intestinal schistosomiasis on the Sesse Islands, Uganda: integrating malacology and parasitology to tailor local treatment recommendations. Parasit Vectors 2010; 3:64.

66. Stothard JR, Sousa-Figueiredo JC, Standley C, Van Dam GJ, Knopp S, Utzinger J, et al. An evaluation of urine-CCA strip test and fingerprick blood SEA-ELISA for detection of urinary schistosomiasis in schoolchildren in Zanzibar. Acta Trop 2009; 111:64-70.

67. Ayele B, Erko B, Legesse M, Hailu A, Medhin G. Evaluation of circulating cathodic antigen (CCA) strip for diagnosis of urinary schistosomiasis in Hassoba school children, Afar, Ethiopia. Parasite 20081 5:69-75.

68. Obeng BB, Aryeetey YA, de Dood CJ, Amoah AS, Larbi IA, Deelder AM, et al. Application of a circulating-cathodic-antigen (CCA) strip test and real-time PCR, in comparison with microscopy, for the detection of Schistosoma haematobium in urine samples from Ghana. Ann Trop Med Parasitol 2008; 102:625-633.

69. Midzi N, Butterworth AE, Mduluza T, Munyati S, Deelder AM, van Dam GJ. Use of circulating cathodic antigen strips for the diagnosis of urinary schistosomiasis. Trans R Soc Trop Med Hyg 2009; 103:45-51.

70. Coulibaly JT, Knopp S, N'Guessan NA, Silué KD, Fürst T, Lohourignon LK, et al. Accuracy of urine circulating cathodic antigen (CCA) test for Schistosoma mansoni diagnosis in different settings of Côte d'Ivoire. PLoS Negl Trop Dis 2011; 5:e1384.

71. Shane HL, Verani JR, Abudho B, Montgomery SP, Blackstock AJ, Mwinzi $\mathrm{PN}$, et al. Evaluation of urine CCA assays for detection of Schistosoma mansoni infection in Western Kenya. PLoS Negl Trop Dis 2011; 5:e951.

72. Ashton RA, Stewart BT, Petty N, Lado M, Finn T, Brooker S, et al. Accuracy of circulating cathodic antigen tests for rapid mapping of Schistosoma mansoni and S. haematobium infections in Southern Sudan. Trop Med Int Health 2011; 16:1099-1103.

73. Reithinger R, Dujardin JC. Molecular diagnosis of leishmaniasis: current status and future applications. J Clin Microbiol 2007; 45:21-25.

74. Pontes LA, Dias-Neto E, Rabello A. Detection by polymerase chain reaction of Schistosoma mansoni DNA in human serum and feces. Am J Trop Med Hyg 2002; 66:157-162.

75. Pontes LA, Oliveira MC, Katz N, Dias-Neto E, Rabello A. Comparison of a polymerase chain reaction and the Kato-Katz technique for diagnosing infection with Schistosoma mansoni. American Journal of Tropical Medicine and Hygiene 2003; 68:652-656.

76. Hamburger J, Turetski T, Kapeller I, Deresiewicz R. Highly repeated short DNA sequences in the genome of Schistosoma mansoni recognized by a species-specific probe. Mol Biochem Parasitol 1991; 44:73-80.

77. Oliveira LM, Santos HL, Gonçalves MM, Barreto MG, Peralta JM. Evaluation of polymerase chain reaction as an additional tool for the diagnosis of low-intensity Schistosoma mansoni infection. Diagn Microbiol Infect Dis 2010; 68:416-421.

78. Carvalho GC, Marques LH, Gomes LI, Rabello A, Ribeiro LC, Scopel KK, et al. Polymerase chain reaction for the evaluation of Schistosoma mansoni infection in two low endemicity areas of Minas Gerais, Brazil. Mem Inst Oswaldo Cruz 2012; 107:899-902.

79. Allam AF, Kader O, Zaki A, Shehab AY, Farag HF. Assessing the marginal error in diagnosis and cure of Schistosoma mansoni in areas of low endemicity using Percoll and PCR techniques. Trop Med Int Health 2009;14:316-321. 
80. Gomes LI, Dos Santos Marques LH, Enk MJ, de Oliveira MC, Coelho PM, Rabello A. Development and evaluation of a sensitive PCR-ELISA system for detection of schistosoma infection in feces. PLoS Negl Trop Dis 2010; 4:e664.

81. Akinwale OP, Laurent T, Mertens P, Leclipteux T, Rollinson D, Kane R, et al. Detection of schistosomes polymerase chain reaction amplified DNA by oligochromatographic dipstick. Mol Biochem Parasitol 2008; 160:167-170.

82. Gomes LI, Marques LH, Enk MJ, Coelho PM, Rabello A. Further evaluation of an updated PCR assay for the detection of Schistosoma mansoni DNA in human stool samples. Mem Inst Oswaldo Cruz 2009;104:1194-1196.

83. Wichmann D, Panning M, Quack T, Kramme S, Burchard GD, Grevelding C, et al. Diagnosing schistosomiasis by detection of cell-free parasite DNA in human plasma. PLoS Negl Trop Dis 2009; 3:e422.

84. Enk MJ, Oliveira e Silva G, Rodrigues NB. A salting out and resin procedure for extracting Schistosoma mansoni DNA from human urine samples. BMC Res Notes 2010; 3:115.

85. Enk MJ, Oliveira e Silva G, Rodrigues NB. Diagnostic accuracy and applicability of a PCR system for the detection of Schistosoma mansoni DNA in human urine samples from an endemic area. PLoS One 2012; 7:e38947.

86. Ibironke OA, Phillips AE, Garba A, Lamine SM, Shiff C. Diagnosis of Schistosoma haematobium by detection of specific DNA fragments from filtered urine samples. Am J Trop Med Hyg 2011; 84:998-1001.

87. Sandoval N, Siles-Lucas M, Pérez-Arellano JL, Carranza C, Puente S, LópezAbán et al. A new PCR-based approach for the specific amplification of DNA from different Schistosoma species applicable to human urine samples. Parasitology 2006; 133:581-587.

88. Lodh N, Mwansa JC, Mutengo MM, Shiff CJ. Diagnosis of Schistosoma mansoni without the stool: comparison of three diagnostic tests to detect Schistosoma mansoni infection from filtered urine in Zambia. Am J Trop Med Hyg 2013; 89:46-50.

89. Gomes AL, Melo FL, Werkhauser RP, Abath FG. Development of a real time polymerase chain reaction for quantitation of Schistosoma mansoni DNA. Mem Inst Oswaldo Cruz 2006; 101 (supl 1:133-136.

90. Lier T, Simonsen GS, Haaheim H, Hjelmevoll SO, Vennervald BJ, Johansen MV. Novel real-time PCr for detection of Schistosoma japonicum in stool. Southeast Asian J Trop Med Public Health 2006; 37:257-264.

91. Lier T, Simonsen GS, Wang T, Lu D, Haukland HH, Vennervald BJ, et al. Realtime polymerase chain reaction for detection of low-intensity Schistosoma japonicum infections in China. Am J Trop Med Hyg 2009; 81:428-432.

92. Aryeetey YA, Essien-Baidoo S, Larbi IA, Ahmed K, Amoah AS, Obeng $\mathrm{BB}$, et al. Molecular diagnosis of Schistosoma infections in urine samples of school children in Ghana. Am J Trop Med Hyg 2013; 88:1028-1031.
93. Cnops L, Tannich E, Polman K, Clerinx J, Van Esbroeck M. Schistosoma real-time PCR as diagnostic tool for international travellers and migrants. Trop Med Int Health 2012; 17:1208-1216.

94. Cnops L, Soentjens P, Clerinx J, Van Esbroeck M. A Schistosoma haematobium-specific real-time PCR for diagnosis of urogenital schistosomiasis in serum samples of international travelers and migrants. PLoS Negl Trop Dis 2013; 7:e2413.

95. Ten Hove RJ, Verweij JJ, Vereecken K, Polman K, Dieye L, van Lieshout L. Multiplex real-time PCR for the detection and quantification of Schistosoma mansoni and $S$. haematobium infection in stool samples collected in northern Senegal. Trans R Soc Trop Med Hyg 2008; 102:179-185.

96. Notomi T, Okayama H, Masubuchi H, Yonekawa T, Watanabe K, Amino $\mathrm{N}$, et al. Loop-mediated isothermal amplification of DNA. Nucleic Acids Res 2000; 28:E63.

97. Xu J, Rong R, Zhang HQ, Shi CJ, Zhu XQ, Xia CM. Sensitive and rapid detection of Schistosoma japonicum DNA by loop-mediated isothermal amplification (LAMP). Int J Parasitol 2010; 40:327-331.

98. Utzinger J, Becker SL, Knopp S, Blum J, Neumayr AL, Keiser J, et al. Neglected tropical diseases: diagnosis, clinical management, treatment and control. Swiss Med Wkly 2012; 142:w13727.

99. Dawson EM, Sousa-Figueiredo JC, Kabatereine NB, Doenhoff MJ, Stothard JR. Intestinal schistosomiasis in pre school-aged children of Lake Albert, Uganda: diagnostic accuracy of a rapid test for detection of anti-schistosome antibodies. Trans R Soc Trop Med Hyg 2013; 107: 639-647.

100.Van Dam GJ, de Dood CJ, Lewis M, Deelder AM, van Lieshout L, Tanke HJ, et al. A robust dry reagent lateral flow assay for diagnosis of active schistosomiasis by detection of Schistosoma circulating anodic antigen. Exp Parasitol 2013; 135:274-282.

101.Coulibaly JT, N'Gbesso YK, Knopp S, N'Guessan NA, Silué KD, van Dam GJ, et al. Accuracy of urine circulating cathodic antigen test for the diagnosis of Schistosoma mansoni in preschool-aged children before and after treatment. PLoS Negl Trop Dis 2013; 7:e2109.

102.Erko B, Medhin G, Teklehaymanot T, Degarege A, Legesse M. Evaluation of urine-circulating cathodic antigen (Urine-CCA) cassette test for the detection of Schistosoma mansoni infection in areas of moderate prevalence in Ethiopia. Trop Med Int Health 2013; 18:1029-1035.

103. Colley DG, Binder S, Campbell C, King CH, Tchuem Tchuenté LA, N'Goran EK, et al. A five-country evaluation of a point-of-care circulating cathodic antigen urine assay for the prevalence of Schistosoma mansoni. Am J Trop Med Hyg 2013; 88:426-434.

104.Guo JG, Cao CL, Hu GH, Lin H, Li D, Zhu R, et al. The role of 'passive chemotherapy' plus health education for schistosomiasis control in China during maintenance and consolidation phase. Acta Trop 2005; 96:177-183. 